\title{
Gene expression analyses identify a relationship between stanniocalcin 2 and the malignant behavior of colorectal cancer
}

Jian Wang'
Sana Sahengbieke ${ }^{2}$
Xiaoping Xu'
Lei Zhang
Xiaoming Xu'
Lifeng Sun'
Qun Deng'
Da Wang'
Dong Chen ${ }^{3}$
Yuan Pan ${ }^{3}$
Zhaohui Liu ${ }^{3}$
Shaojun Yu'
'Department of Surgical Oncology,
Second Affiliated Hospital, Zhejiang
University School of Medicine,
Hangzhou, Zhejiang Province, People's
Republic of China; ${ }^{2}$ Department
of Pathology, Zhejiang University
School of Medicine, Hangzhou,
Zhejiang Province, People's Republic
of China; ${ }^{3}$ Department of Anorectal
Surgery, Yuhang District First
People's Hospital, Hangzhou, Zhejiang
Province, People's Republic of China;
${ }^{4}$ Department of Pathology, Second
Affiliated Hospital, Zhejiang University
School of Medicine, Hangzhou,
Zhejiang Province, People's Republic
of China

Correspondence: Shaojun Yu Department of Surgical Oncology, Second Affiliated Hospital, Zhejiang University School of Medicine, 88 Jiefang Road, Hangzhou 310009, People's Republic of China Tel +86 57I 87783586 Fax +86 57I 8778450 I Email jackdavid1982@zju.edu.cn
This article was published in the following Dove Press journal: OncoTargets and Therapy

Background: Colorectal cancer (CRC) is one of the main causes of cancer-related death worldwide. Stanniocalcin 2 (STC2), a secreted glycoprotein, has been suggested to exert various functions in progression of many cancers. However, the precise biological role in CRC is not fully understood. Therefore, this study based on several public datasets aims at investigating the roles of STC2 in CRC.

Methods: We used The Cancer Genome Atlas (TCGA) and Gene Expression Omnibus (GEO) databases to evaluate the STC2 expression and its clinical significance in CRC. Cell migration and invasion by STC2 overexpression and knockdown were assessed using Transwell migration and Matrigel invasion assays. We next performed RNAseq analysis on SW480 cells with or without STC2 overexpression. Differentially expressed genes were selected by using foldchange $>5$ and $P$-value $<0.05$.

Results: In this study, we found that STC2 level was significantly higher in CRC than that in adjacent noncancerous tissues from TCGA and GEO. Tumors with high mRNA levels of STC2 were more common in patients with rectal cancer, left-sided CRC, advanced T-stage (T3-T4), positive lymph node involvement and advanced AJCC-stage (III-IV) from TCGA. STC2 displayed the negative correlation with the expressions of epithelial cell markers, while it was positively correlated with the expressions of mesenchymal cell markers, MMPs and the epithelial-mesenchymal transition (EMT)-related transcriptional factors. Furthermore, we found that STC2 promoted cell migration and invasion in vitro. And a group of differentially expressed genes, which were modulated by STC2, were identified from RNAseq analyses.

Conclusion: Our study demonstrates that STC2 is overexpressed in CRC compared with normal tissues, and promotes CRC cell migration and invasion. Our data suggest that STC2 may be used as a potential biomarker for clinical application and target therapy in future.

Keywords: stanniocalcin 2, colorectal cancer, TCGA, RNAseq

\section{Introduction}

Colorectal cancer (CRC) is one of the most common causes of morbidity and mortality globally, and the leading cause of death among cancer patients is metastasis. ${ }^{1}$ Current studies have revealed that the carcinogenesis of CRC is a multi-step process, which requires the accumulation of genetic and epigenetic changes. ${ }^{2}$ Although great advances have been made in elucidating the molecular basis of $\mathrm{CRC}$, the exact mechanism underlying the pathogenesis of CRC remains unclear. Therefore, novel molecular biomarkers need to be identified in the future.

The Cancer Genome Atlas (TCGA) Research Network, which is supervised by the National Cancer Institute and the National Human Genome Research Institute, is 
a consortium to analyze the molecular profiling and clinical parameters of 34 different tumor types on multiple levels (nucleotide mutation, copy number variation, mRNA expression, DNA methylation, and protein expression). ${ }^{3}$

The Gene Expression Omnibus (GEO) database established by the National Center for Biotechnology Information is a public community resource containing all high-throughput gene expression data from different types of species, diseases, and experimental conditions. ${ }^{4}$ Eight gene expression profiles of CRC were used in this study, including GSE18105, ${ }^{5}$ GSE20842, ${ }^{6}$ GSE21510, ${ }^{7}$ GSE24514, ${ }^{8}$ GSE41011, ${ }^{9}$ GSE44861, ${ }^{10}$ GSE47063, ${ }^{11}$ and GSE54986. ${ }^{12}$

Stanniocalcins (STCs) are secreted glycoproteins, which were originally identified in the corpuscles of Stannius in bony fish. ${ }^{13}$ The STC family includes two members, STC1 and STC2, both of which are highly conserved and play important roles in regulating calcium and phosphate homeostasis. ${ }^{13}$ More importantly, there is now increasing evidence of the roles of STC2 in progression of cancers. When compared with the relevant normal tissues, higher expression levels of STC2 were detected in various cancers, such as ovarian, ${ }^{14}$ gastric, ${ }^{15}$ and colorectal. ${ }^{16-19}$ Furthermore, STC2 was reported to be a predictive marker for tumor grade, invasiveness, metastasis, chemoresistance, recurrence, and prognosis. ${ }^{18,20}$ It was demonstrated that STC2 was associated with unfavorable overall survival in $\mathrm{CRC} .{ }^{18} \mathrm{Chen}$ et a ${ }^{17}$ found that STC2 promoted the epithelial-mesenchymal transition (EMT) process via AKT-ERK signaling in CRC. In addition, Yuan et $\mathrm{al}^{19}$ reported that STC2-induced chemoresistance is partly mediated by modulating the expression of P-glycoprotein. However, the precise role of STC2 in CRC remains to be investigated. Therefore, a study based on several public datasets was employed here.

In the present study, we found that CRC tissue exhibited an increased expression of STC2 in TCGA and GEO datasets when compared with normal tissue. It was demonstrated that the high expression of STC2 was strongly associated with tumor location, T stage, lymph node involvement, and American Joint Committee on Cancer (AJCC) stage from the TCGA dataset. The correlation analysis from TCGA showed that STC2 displayed a positive correlation with the expression of the mesenchymal cell markers, matrix metalloproteinases (MMPs), and the EMT-related transcriptional factors. But a negative correlation between the levels of STC2 and the epithelial cell markers was observed from TCGA dataset. Furthermore, we also found that STC2 promoted migration and invasion of CRC cells in vitro through modulating a group of differentially expressed genes (DEGs) by RNAseq analyses.

\section{Materials and methods TCGA database}

We extracted the gene expression data and corresponding clinicopathological data for 383 CRC patients from TCGA (https://cancergenome.nih.gov/). The statistical differences of gene expression levels were analyzed by Mann-Whitney Wilcoxon test or Student's $t$-test according to the distribution of the variables. The results were presented as mean $\pm \mathrm{SD}$ of samples. We used Pearson's $R$ correlation coefficient to assess relationships between the mRNA expression levels of STC2 and other genes. $P<0.05$ was considered as statistically significant.

\section{GEO database}

The gene expression profiles (GSE18105, GSE20842, GSE21510, GSE24514, GSE41011, GSE44861, GSE47063, and GSE54986) were downloaded from GEO (https://www. ncbi.nlm.nih.gov/gds/). Then we extracted STC2 expression data and employed Mann-Whitney Wilcoxon test or Student's $t$-test to assess statistical differences in STC2 expression levels between CRC and normal control tissues. $P<0.05$ was considered as statistically significant.

\section{Cell culture}

Human CRC cell lines SW480, DLD1, HCT116, and RKO were obtained from the American Type Culture Collection. All the cells were maintained in RPMI 1640 medium supplemented with 10\% FBS (Thermo Fisher Scientific, Waltham, MA, USA) in the atmosphere of $37^{\circ} \mathrm{C}$ containing $5 \% \mathrm{CO}_{2}$.

\section{Lentivirus-mediated STC2 overexpression and knockdown}

To generate the STC2 overexpression vector, the full-length open reading frame of human STC2 cDNA was originally cloned by PCR into pHBLV-Luc lentiviral vectors. For the knockdown of STC2, small hairpin RNA (shRNA) targeting STC2 gene was cloned into pGIPZ lentiviral constructs. The target sequence of STC2 used here was 5'-GGGCAAGTCATTCATCAAAGA-3'. Then the envelope plasmids (pMD2G) and lentiviral packaging plasmids (psPAX2) were co-transfected with pHBLV-Luc or pGIPZ plasmids into HEK293T cells with Lipofectamine 2000 (Thermo Fisher Scientific) according to the manufacturer's instructions. After 24 hours, the supernatants were collected, and the corresponding cells were infected with lentivirus. Stable cell lines were selected in RPMI 1640 medium containing $2 \mu \mathrm{g} / \mathrm{mL}$ puromycin (Sigma-Aldrich Co., St Louis, MO, USA) and confirmed by Western blot analysis. 


\section{Cell migration and invasion assays}

A total of $1 \times 10^{4}$ cells in $200 \mu \mathrm{L}$ serum-free medium were seeded into the upper side of 24-well Transwell chambers (Corning Incorporated, Corning, NY, USA) coated with or without Matrigel (BD Biosciences, San Jose, CA, USA). Then, RPMI 1640 medium with $10 \%$ FBS was added to the lower chamber. After 48 hours, cells on the lower surface of the chambers were stained with $0.1 \%$ crystal violet, and then cells were counted. Each experiment was repeated at least three times.

\section{Western blot analysis}

Total proteins were extracted from cells using the Protein Extraction Reagent (Thermo Fisher Scientific). Equal amounts $(30 \mu \mathrm{g})$ of protein were separated on SDS-PAGE gels and then transferred to polyvinylidene difluoride membranes (EMD Millipore, Billerica, MA, USA). The membranes were blocked with 5\% fat-free dried milk and then probed with primary antibodies against STC2 (Abcam, Cambridge, MA, USA; 1:200) and $\beta$-actin (Sigma-Aldrich Co., St. Louis, MO, USA; $1: 1,000)$. $\beta$-actin served as a loading control.

\section{RNA-sequencing analysis}

Total RNA was obtained from SW480 with or without STC2 overexpression (SW480-NC and SW480-STC2) by using RNeasy Mini Kit (Qiagen, Germantown, MD, USA). RNAseq library was prepared for each cDNA sample using the Illumina TruSeq Stranded mRNA Sample Prep Kit (Illumina, San Diego, CA, USA) according to the manufacturer's protocol. Sequencing was performed on the Illumina
HiSeq platform 2,500 platform (Illumina) by Aksomics (Shanghai, People's Republic of China). Transcript FPKM was used as the measurement of transcript expression. DEGs were selected by using fold-change $>5$ and $P$-value $<0.05$. RNA-sequencing datasets have been deposited into the NCBI with the accession number GSE116521.

\section{Statistics analyses}

Statistical analyses were performed using SPSS 17.0 software package (SPSS Inc., Chicago, IL, USA) and GraphPad Prism 5. All data were presented as mean \pm SD of at least three independent experiments. Student's $t$-test was used for comparisons between two groups of in vitro experiments in cell lines. $P<0.05$ was considered statistically significant.

\section{Results \\ Increased expression of STC2 in CRC from TCGA and GEO}

To investigate the expression pattern of STC2 in CRC, we compared the STC2 expression levels in CRC and normal tissue samples from TCGA and GEO. The TCGA for CRC contained $383 \mathrm{CRC}$ and 50 normal tissue samples, while the GSE18105, GSE20842, GSE41011, GSE44861, and GSE54986 datasets included 17, 65, 11, 47, and 6 paired CRC and normal control tissue samples, respectively. The GSE21510 contained $19 \mathrm{CRC}$ and 25 non-tumor adjacent tissues, whereas GSE24514 contained $34 \mathrm{CRC}$ and 15 non-tumor adjacent tissues. Fourteen $\mathrm{CRC}$ and four surrounding normal tissue samples were included in GSE47063. All GEO databases

Table I Characteristics of GEO datasets collected from NCBI databases

\begin{tabular}{|c|c|c|c|c|c|c|c|c|c|}
\hline \multirow{2}{*}{$\begin{array}{l}\text { First author } \\
\text { (publication year) }\end{array}$} & \multirow[t]{2}{*}{ Country } & \multirow[t]{2}{*}{ Dataset } & \multirow[t]{2}{*}{ Platform } & \multicolumn{3}{|c|}{ Cancer } & \multicolumn{3}{|c|}{ Non-tumor } \\
\hline & & & & $\mathbf{n}$ & Mean & SD & $\mathbf{n}$ & Mean & SD \\
\hline $\begin{array}{l}\text { Matsuyama et al } \\
(2010)\end{array}$ & Japan & GEO:GSEI8I05 & $\begin{array}{l}\text { Affymetrix } \\
\text { GPL570 }\end{array}$ & 17 & 6.909495 & $0.988 \mid 22$ & 17 & 5.323416 & 0.284383 \\
\hline $\begin{array}{l}\text { Gaedcke et al } \\
(2010)\end{array}$ & Germany & GEO:GSE20842 & $\begin{array}{l}\text { Agilent } \\
\text { GPL4I33 }\end{array}$ & 65 & 8.751249 & 1.000798 & 65 & 6.585917 & 0.206843 \\
\hline $\begin{array}{l}\text { Tsukamoto et al } \\
\text { (20II) }\end{array}$ & Japan & GEO:GSE2। 510 & $\begin{array}{l}\text { Affymetrix } \\
\text { GPL570 }\end{array}$ & 19 & 6.923814 & 0.896744 & 25 & 5.465800 & 0.234194 \\
\hline $\begin{array}{l}\text { Alhopuro et al } \\
(20 I 2)\end{array}$ & Finland & GEO:GSE245I4 & $\begin{array}{l}\text { Affymetrix } \\
\text { GPL96 }\end{array}$ & 34 & 6.204555 & 0.510792 & 15 & 5.913547 & 0.269686 \\
\hline Sun et al (20|4) & $\begin{array}{l}\text { People's Republic } \\
\text { of China }\end{array}$ & GEO:GSE4I0I I & $\begin{array}{l}\text { Phalanx } \\
\text { GPL6254 }\end{array}$ & II & 4.028934 & 0.394237 & 11 & 3.708407 & 0.182433 \\
\hline $\begin{array}{l}\text { Ryan et al } \\
(2014)\end{array}$ & USA & GEO:GSE4486I & $\begin{array}{l}\text { Affymetrix } \\
\text { GPL392I }\end{array}$ & 47 & 6.826138 & 0.958492 & 47 & 6.093771 & 0.448783 \\
\hline $\begin{array}{l}\text { Uribe-Lewis et al } \\
(2015)\end{array}$ & UK & GEO:GSE47063 & $\begin{array}{l}\text { Illumina } \\
\text { GPL6102 }\end{array}$ & 14 & 8.145573 & 1.651213 & 4 & 5.239302 & 0.434514 \\
\hline Ding et al (20I6) & $\begin{array}{l}\text { People's Republic } \\
\text { of China }\end{array}$ & GEO:GSE54986 & $\begin{array}{l}\text { Illumina } \\
\text { GPLI0558 }\end{array}$ & 6 & 336.666667 & 176.569889 & 6 & 69.597542 & 8.612638 \\
\hline
\end{tabular}

Abbreviation: GEO, Gene Expression Omnibus. 

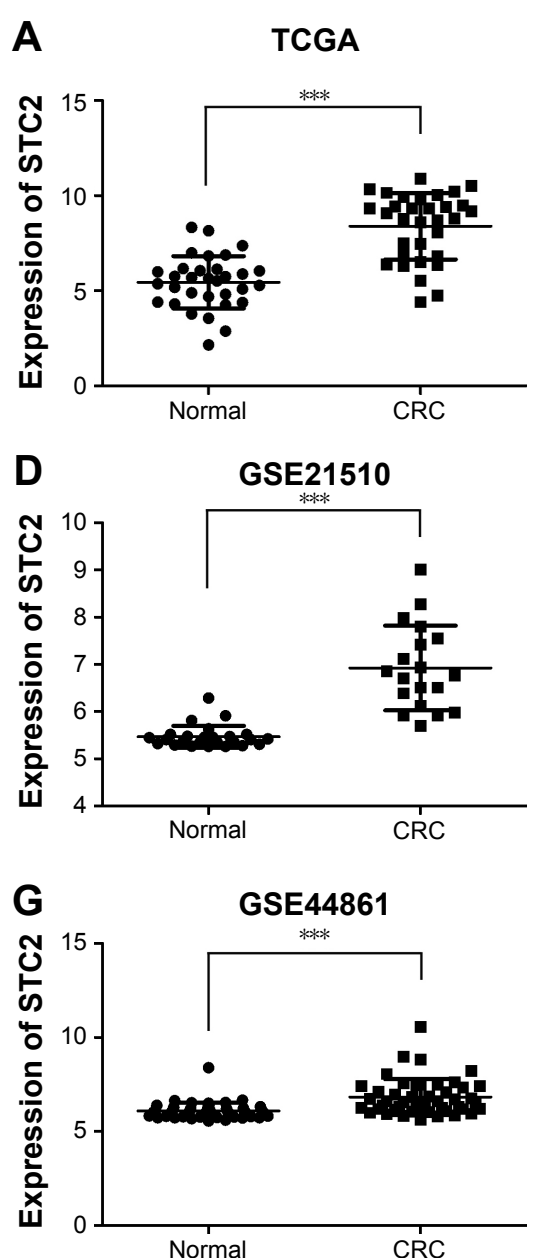
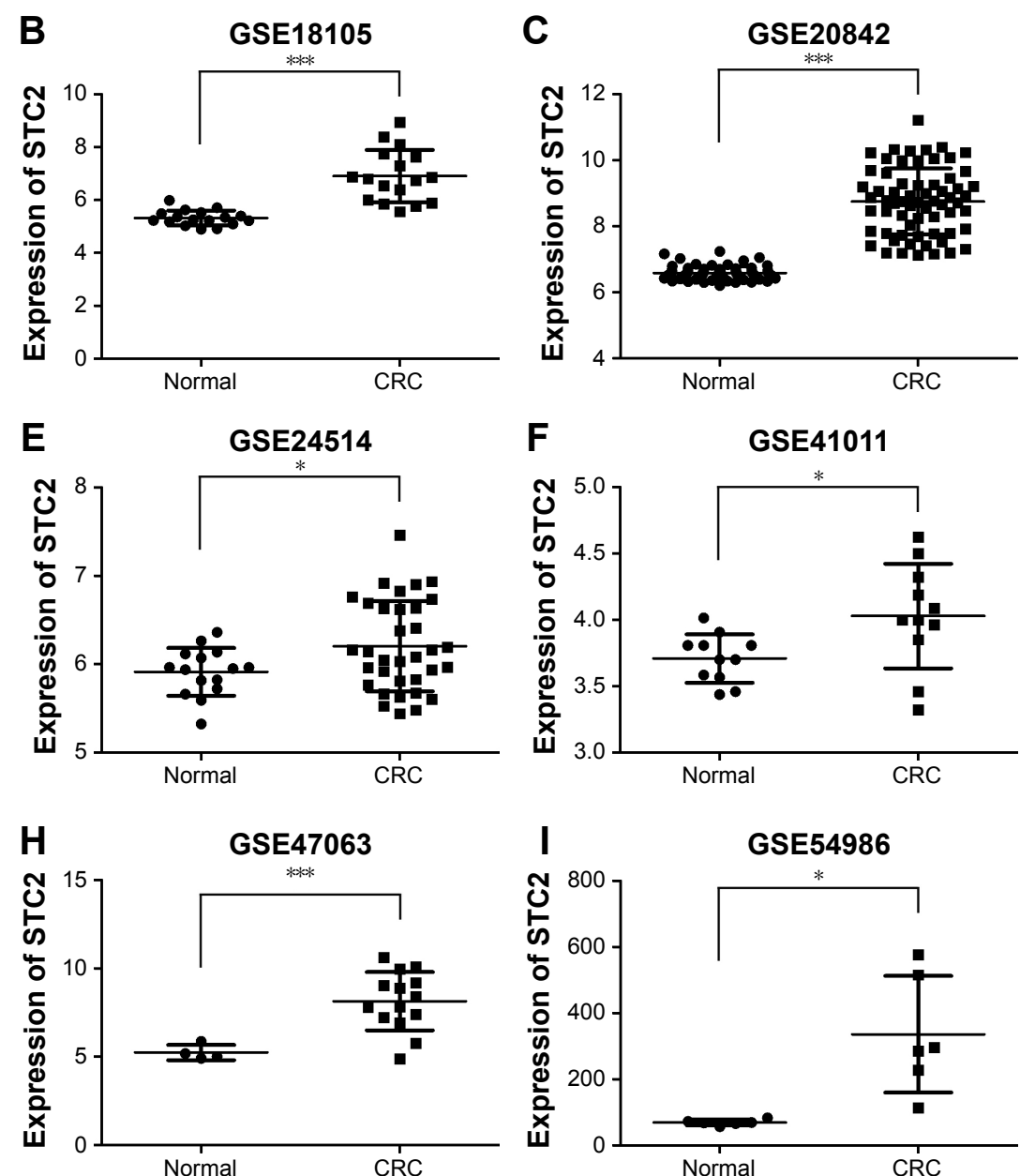

Figure I An increased expression of STC2 in CRC from TCGA and GEO.

Notes: Expression levels of STC2 were higher in CRC tissues compared with the adjacent normal tissues in TCGA (A), GSEI8I05 (B), GSE20842 (C), GSE2I5I0 (D), GSE245I 4 (E), GSE4I0I I (F), GSE4486I (G), GSE47063 (H), and GSE54986 (I). *P<0.05; ***P<0.00I.

Abbreviations: CRC, colorectal cancer; STC2, stanniocalcin 2; TCGA, The Cancer Genome Atlas.

are summarized in Table 1. Consistent with the results from the TCGA datasets (Figure 1A; 8.393 \pm 1.751 vs 5.445 \pm 1.372 , $P<0.001)$, STC2 mRNA level was significantly higher in CRC than that in adjacent noncancerous tissues from GSE18105 (Figure 1B; 6.909 \pm 0.988 vs 5.323 $\pm 0.284, P<0.001$ ), GSE20842 (Figure 1C; $8.751 \pm 1.001$ vs 6.586 $\pm 0.207, P<0.001$ ), GSE2 1510 (Figure 1D; 6.924 \pm 0.897 vs 5.466 $\pm 0.234, P<0.001$ ), GSE24514 (Figure 1E; 6.205 \pm 0.511 vs 5.914 $\pm 0.270, P=0.013$ ), GSE41011 (Figure 1F; $4.029 \pm 0.394$ vs $3.708 \pm 0.182, P=0.024)$, GSE44861 (Figure $1 \mathrm{G} ; 6.826 \pm 0.958$ vs $6.094 \pm 0.449, P<0.001$ ), GSE47063 (Figure 1H; 8.146 \pm 1.651 vs 5.239 \pm 0.435 , $P<0.001$ ), and GSE54986 (Figure 1I; 336.667 \pm 176.570 vs $69.598 \pm 8.613, P=0.014)$. Together, these results indicated that STC2 had potential pro-tumorigenic effects in CRC.

\section{Promoting effect of STC2 on migration and invasion of CRC cells in vitro}

To give a better understanding of STC2 in CRC, we analyzed the basal expression of STC2 protein in CRC cell lines including SW480, DLD1, HCT116, and RKO. As shown in Figure 2A, it seemed that STC2 had high levels in HCT116 and RKO cells, but low in SW480 and DLD1 cells. So SW480 and DLD1 cells were chosen to adopt overexpression of STC2, whereas HCT116 and RKO cells were chosen to adopt inhibition of STC2. Then we conducted the functional analysis in CRC cells in vitro. First, the efficiency of STC2 overexpression and silence was assessed by Western blotting. As shown in Figure 2B, the expression level of STC2 was markedly augmented after transfection with STC2-overexpressed plasmids in SW480 and DLD1 cells, while it was significantly inhibited after transfection with STC2 shRNA vectors in HCT116 and RKO cells. Then, transwell and matrigel assays were conducted to evaluate the effects of STC2 on the migratory and the invasive potential of CRC cells. Overexpression of STC2 significantly facilitated migration and invasion of SW480 and DLD1 cells compared with control cells (Figure 2C). Consistently, knockdown of STC2 impaired it (Figure 2C), indicating that STC2 might play important roles in CRC metastasis. 


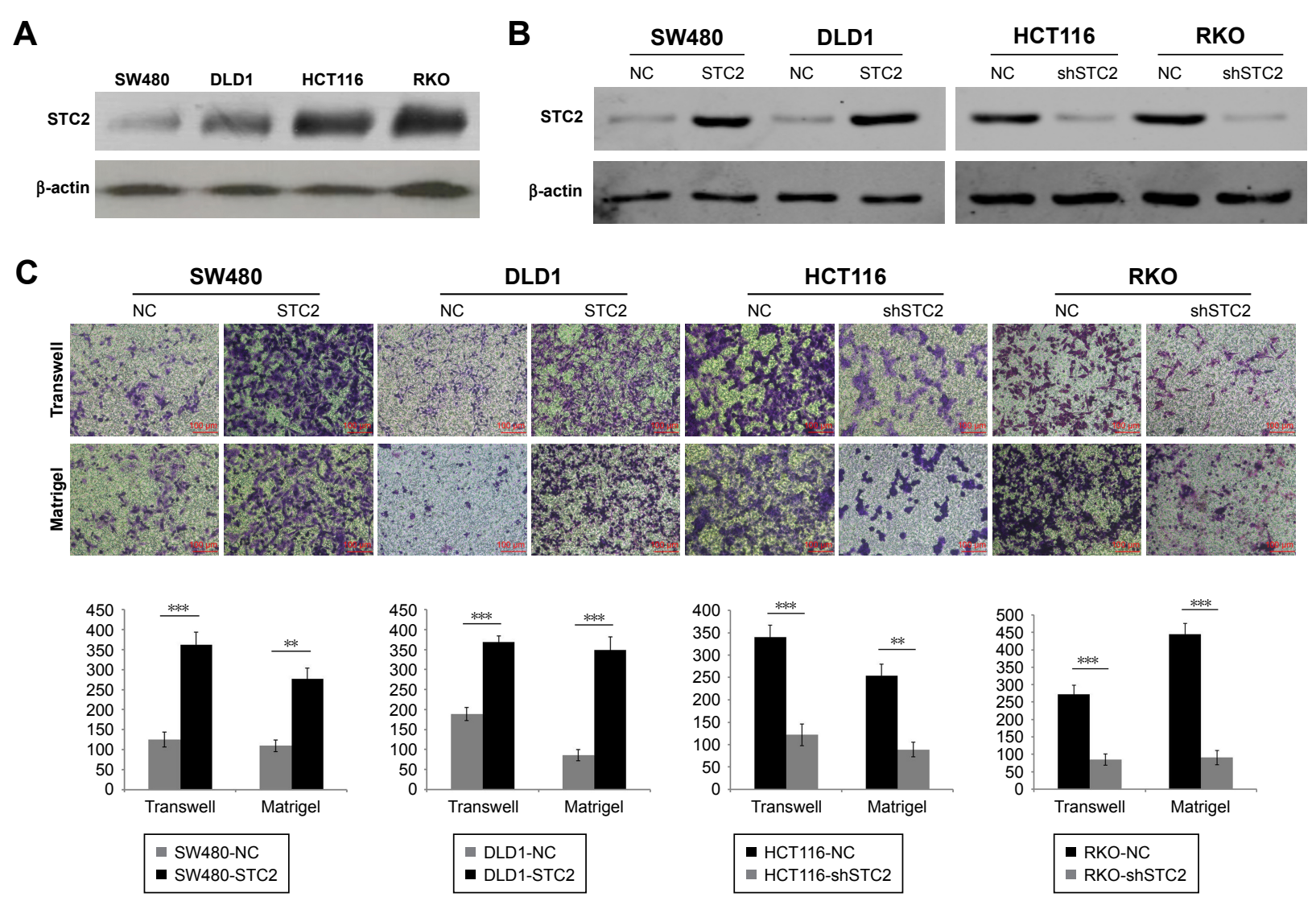

Figure 2 Promoting effect of STC2 on migration and invasion of CRC cells in vitro.

Notes: (A) The basal protein levels of STC2 in SW480, DLDI, HCTI I6, and RKO cells by Western blot analysis. $\beta$-Actin was used as a loading control. (B) The protein levels of STC2 were confirmed by Western blot analysis in SW480 and DLDI cells with or without STC2 overexpression and in HCTII6 and RKO cells with or without STC2 knockdown. B-Actin was used as a loading control. (C) Transwell migration and invasion assays were employed in SW480 and DLDI cells with or without STC2 overexpression and in HCTII6 and RKO cells with or without STC2 knockdown. The representative images (top) and bar graphs (bottom) were shown. **P $<0.01$, $* * * P<0.001$.

Abbreviations: CRC, colorectal cancer; STC2, stanniocalcin 2.

\section{Association of STC2 expression with clinicopathological parameters from TCGA dataset}

To define the role of STC 2 in CRC, we further determine the relationship between STC 2 expression and the clinicopathological characteristics of 383 CRC patients from TCGA dataset. The clinical features were summarized in Table 2, including age, gender, tumor location, tumor size, microsatellite instability (MSI) status, history of colon polyps, KRAS mutation status, venous invasion status, TNM stage, and AJCC stage. As shown in Table 2, the expression level of STC2 mRNA increased in patients with rectal cancer compared with that in patients with colon cancer $(9.057 \pm 1.399$ vs $8.542 \pm 1.829$, $P=0.005)$, increased in patients with left-sided CRC compared with that in patients with right-sided CRC $(9.065 \pm 1.366$ vs $8.151 \pm 1.981, P<0.001)$, increased in stages T3-T4 compared with stages T1-T2 $(8.823 \pm 1.598$ vs $7.890 \pm 2.071, P<0.001)$, increased in patients with positive lymph node involvement compared with that in patients with negative lymph node involvement ( $8.946 \pm 1.592$ vs $8.387 \pm 1.841, P=0.002)$, and increased in AJCC stages III-IV compared with AJCC stages I-II $(8.894 \pm 1.621$ vs $8.404 \pm 1.850, P=0.008)$. However, no associations were observed between STC2 expression and clinical parameters, such as age, gender, tumor size, MSI status, history of colon polyps, KRAS mutation status, venous invasion status, and distant metastasis (Table 2; $P>0.05$ ).

\section{Correlation between STC2 expression and EMT-related markers from analysis of the TCGA dataset}

To elucidate the mechanisms underlying STC2-mediated EMT, we sought to examine the correlation between the expression of STC2 and the epithelial and mesenchymal markers, EMT-related transcriptional factors, and MMPs from TCGA datasets. Consistent with the induction of EMT, STC2 levels were found to be significantly inversely correlated with the expression of the epithelial cell markers (Figure $3 \mathrm{~A})$, such as E-cadherin $(R=-0.110, P=0.022)$, 
Table 2 Relationship between the expression of STC2 and clinicopathologic characteristics from TCGA

\begin{tabular}{|c|c|c|c|c|}
\hline Parameters & Patients (n) & Mean & P25, P75 & $P$-value \\
\hline Age (years) & & & & 0.113 \\
\hline$\leq 65$ & 184 & 8.780 & $(7.728,10.019)$ & \\
\hline$>65$ & 190 & 8.494 & $(7.253,10.050)$ & \\
\hline Gender & & & & 0.709 \\
\hline Male & 206 & 8.665 & $(7.549,10.053)$ & \\
\hline Female & 168 & 8.598 & $(7.509,9.988)$ & \\
\hline Position & & & & $0.005^{\mathrm{a}}$ \\
\hline Colon & 288 & 8.542 & $(7.242,10.047)$ & \\
\hline Rectum & 95 & 9.057 & $(8.074,10.238)$ & \\
\hline Position & & & & $0.000^{\mathrm{a}}$ \\
\hline Left & 194 & 9.065 & $(8.079,10.115)$ & \\
\hline Right & 176 & 8.151 & $(6.757,9.765)$ & \\
\hline Tumor size (cm) & & & & 0.739 \\
\hline$\leq \mathrm{I} .2$ & 129 & 8.628 & $(7.372,10.047)$ & \\
\hline$>1.2$ & 114 & 8.701 & $(7.665,9.829)$ & \\
\hline MSI & & & & 0.122 \\
\hline Negative & 258 & 8.774 & $(7.749,10.083)$ & \\
\hline Positive & 120 & 8.457 & $(7.089,9.973)$ & \\
\hline History of colon polyps & & & & 0.077 \\
\hline No & 186 & 8.751 & $(7.623,10.003)$ & \\
\hline Yes & 80 & 8.368 & $(7.155,9.625)$ & \\
\hline KRAS mutation & & & & 0.270 \\
\hline Negative & 32 & 9.277 & $(8.405,10.300)$ & \\
\hline Positive & 27 & 8.852 & $(7.626,10.091)$ & \\
\hline Venous invasion & & & & 0.291 \\
\hline Negative & 248 & 8.698 & $(7.545,10.065)$ & \\
\hline Positive & 73 & 8.460 & $(7.321,9.720)$ & \\
\hline T stage & & & & $0.000^{\mathrm{a}}$ \\
\hline $\mathrm{TI}+\mathrm{T} 2$ & 69 & 7.890 & $(6.793,9.300)$ & \\
\hline $\mathrm{T} 3+\mathrm{T} 4$ & 302 & 8.823 & $(7.665,10.107)$ & \\
\hline Lymph node & & & & $0.002^{\mathrm{a}}$ \\
\hline Negative & 204 & 8.387 & $(7.130,9.901)$ & \\
\hline Positive & 165 & 8.946 & $(8.020,10.173)$ & \\
\hline Metastasis & & & & 0.139 \\
\hline Negative & 251 & 8.631 & $(7.530,10.053)$ & \\
\hline Positive & 49 & 8.972 & $(8.098,10.038)$ & \\
\hline AJCC stage & & & & $0.008^{a}$ \\
\hline$I+I I$ & 192 & 8.404 & $(7.130,9.938)$ & \\
\hline III + IV & 168 & 8.894 & $(7.972,10.174)$ & \\
\hline
\end{tabular}

Note: ${ }^{a}<0.05$, statistical significance.

Abbreviations: AJCC, American Joint Committee on Cancer; MSI, microsatellite instability; STC2, stanniocalcin 2; TCGA, The Cancer Genome Atlas.

desmoplakin $(R=-0.181, P<0.001)$, and occludin $(R=-0.167$, $P<0.001)$. Conversely, a strong positive correlation between the mRNA levels of STC 2 and the mesenchymal cell markers was observed from the TCGA dataset analysis (Figure 3B), including $\mathrm{N}$-cadherin $(R=0.116, P=0.016)$, fibronectin 1
(FN1; $R=0.324, P<0.001)$, goosecoid $(R=0.260, P<0.001)$, and FOXC2 $(R=0.186, P<0.001)$. Interestingly, our results demonstrated that STC2 mRNA expression was closely related with MMP2 (Figure 3C; $R=0.147, P=0.002$ ), MMP3 (Figure 3C; $R=0.374, P<0.001$ ), and MMP9 (Figure 3C; 


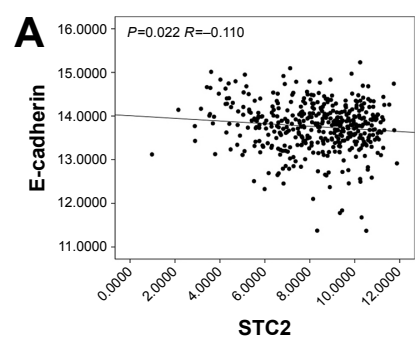

STC2
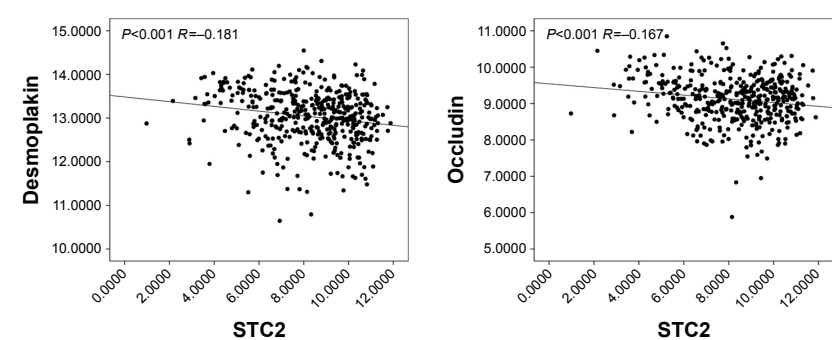
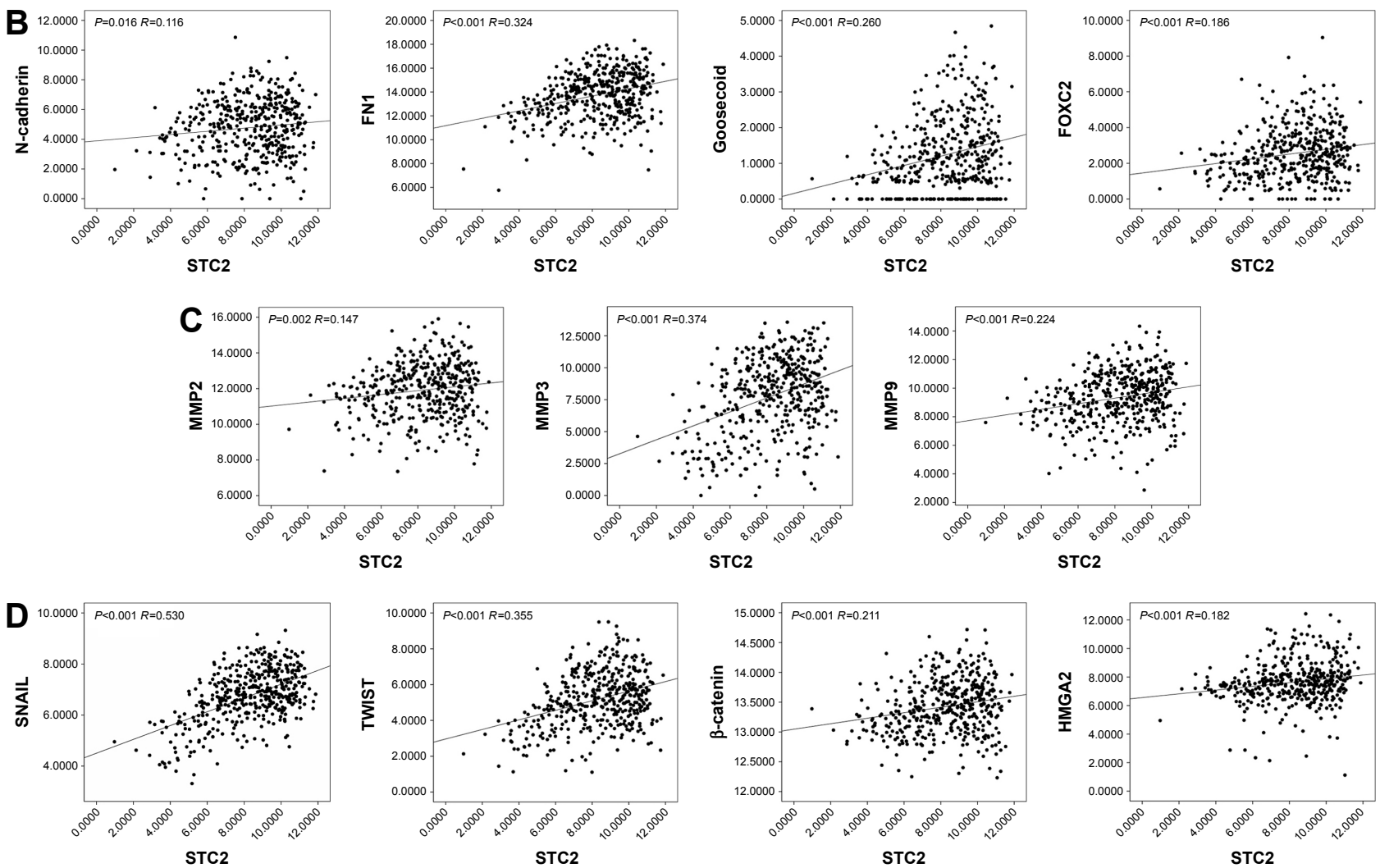

Figure 3 Correlation between STC2 expression and EMT-related markers from analysis of the TCGA dataset.

Notes: (A) The negative correlation between the expression of STC2 and the epithelial cell markers (E-cadherin, desmoplakin, and Occludin) was illustrated in scatter plot from TCGA dataset. (B-D) The positive correlation between the expression of STC2 and (B) the mesenchymal cell markers (N-cadherin, FNI, goosecoid, and FOXC2), (C) the MMPs (MMP2, MMP3, and MMP9), and (D) the EMT-related transcriptional factors (SNAIL, TWIST, $\beta$-catenin, and HMGA2) was illustrated in scatter plot from TCGA dataset. $P$-value represents the statistical results of the Pearson correlation analysis.

Abbreviations: EMT, epithelial-mesenchymal transition; FNI, fibronectin I; MMP, metalloproteinase; STC2, stanniocalcin 2; TCGA, The Cancer Genome Atlas.

$R=0.224, P<0.001)$. In addition, EMT-related transcriptional factors displayed the positive correlation with STC2 (Figure 3D), including SNAIL ( $R=0.530, P<0.001)$, TWIST ( $R=0.355, P<0.001), \beta$-catenin $(R=0.211, P<0.001)$, and HMGA2 $(R=0.182, P<0.001)$. Taken together, all these results suggested that STC2 promoted CRC metastasis through EMT signaling.

\section{Identification of DEGs induced by STC2 overexpression from RNAseq}

To further determine the differences in global gene expression profile by STC2, we performed RNAseq on SW480 cells with or without STC2 overexpression (SW480-NC vs
SW480-STC2). We found that 429 genes showed at least 4-fold increase and 408 genes showed at least 4-fold decrease in SW480-STC2 cells when compared with scramble controls. Candidate genes upregulated $(>7$-fold; Figure $4 \mathrm{~A}$ and Table 3 ) or downregulated by STC2 ( $>5$-fold; Figure $4 \mathrm{~A}$ and Table 4) were selected and summarized. Next, we investigated the expression patterns of these target genes in TCGA dataset. As shown in Figure 4B, the correlation analysis demonstrated that STC2 expression displayed strong positive correlation with coiled-coil domain containing $85 \mathrm{~B}$ (CCDC85B; $R=0.333$, $P<0.001)$, tumor-associated calcium signal transducer 2 (TACSTD2; $R=0.200, P<0.001$ ), ring finger protein $113 \mathrm{~A}$ (RNF113A; $R=0.225, P<0.001$ ), neurexophilin 4 (NXPH4; 

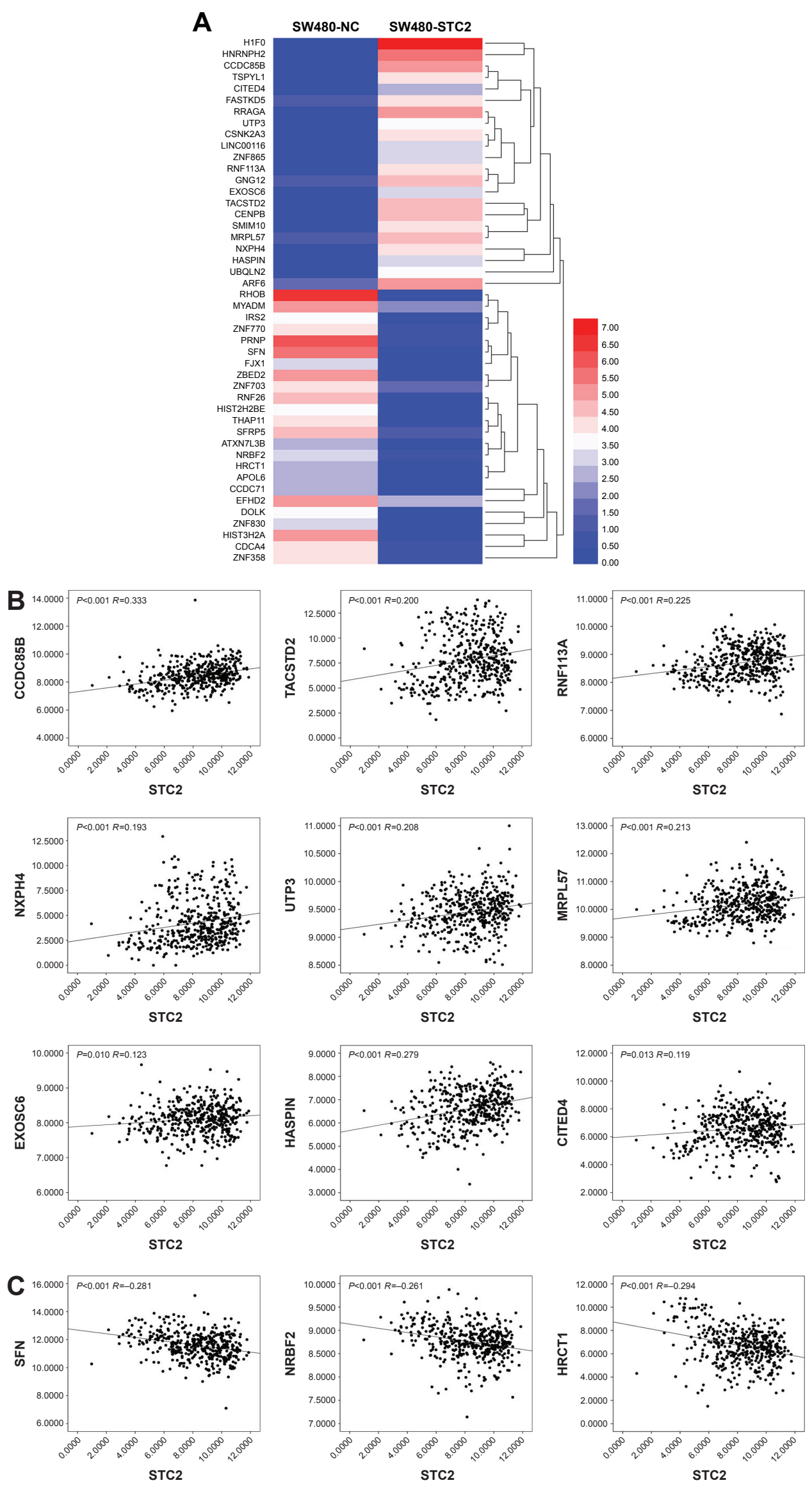

Figure 4 (Continued) 


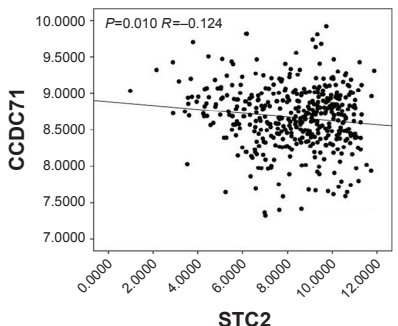

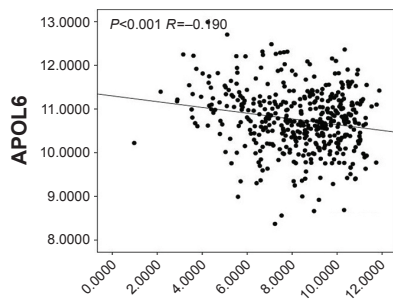

STC2

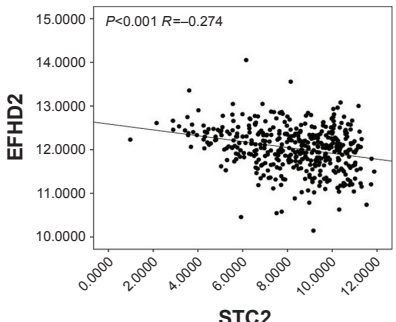

STC2

Figure 4 Identification of DEGs induced by STC2 overexpression from RNAseq

Notes: (A) The clustering heatmap of the significantly dysregulated genes in SW480 cells transfected with empty vector (SW480-NC) or STC2 expression vector (SW480-STC2). (B) The positive correlation between CCDC85B, TACSTD2, RNFII3A, NXPH4, UTP3, MRPL57, EXOSC6, HASPIN or CITED4, and STC2 expression was illustrated in scatter plot from TCGA dataset. (C) The negative correlation between SFN, NRBF2, HRCTI, CCDC7I, APOL6, or EFHD2, and STC2 expression was illustrated in scatter plot by Pearson correlation analysis from TCGA dataset. $P$-value represents the statistical results of the Pearson correlation analysis.

Abbreviations: APOL6, apolipoprotein L6; CCDC7I, coiled-coil domain containing 7I; CCDC85B, coiled-coil domain containing 85B; CITED4, Cbp/p300 interacting transactivator with Glu/Asp-rich carboxy-terminal domain 4; DEG, differentially expressed gene; EFHD2, EF-hand domain family member D2; EXOSC6, exosome component 6; HASPIN, histone H3 associated protein kinase; HRCTI, histidine-rich carboxyl terminus I; MMP, metalloproteinase; MRPL57, mitochondrial ribosomal protein L57; NRBF2, nuclear receptor-binding factor 2; NXPH4, neurexophilin 4; RNFI I3A, ring finger protein II3A; SFN, stratifin; STC2, stanniocalcin 2; TACSTD2, tumor-associated calcium signal transducer 2; TCGA, The Cancer Genome Atlas.

Table 3 List of candidate genes upregulated by STC2 from RNA-seq

\begin{tabular}{|c|c|c|}
\hline Gene symbol & Fold change & Description \\
\hline HIFO & 342.003174 & $\mathrm{HI}$ histone family member 0 \\
\hline HNRNPH2 & 57.233059 & $\begin{array}{l}\text { Heterogeneous nuclear } \\
\text { ribonucleoprotein } \mathrm{H} 2\end{array}$ \\
\hline$C C D C 85 B$ & 39.787907 & $\begin{array}{l}\text { Coiled-coil domain containing } \\
85 \mathrm{~B}\end{array}$ \\
\hline RRAGA & 36.407345 & Ras-related GTP-binding A \\
\hline TACSTD2 & 31.624689 & $\begin{array}{l}\text { Tumor-associated calcium signal } \\
\text { transducer } 2\end{array}$ \\
\hline CENPB & 31.29068 & Centromere protein B \\
\hline RNFII $3 \mathrm{~A}$ & 21.269817 & Ring finger protein II $3 \mathrm{~A}$ \\
\hline TSPYLI & 20.866106 & TSPY like I \\
\hline SMIMIO & 17.073034 & $\begin{array}{l}\text { Small integral membrane protein } \\
10\end{array}$ \\
\hline CSNK2A3 & 16.724165 & Casein kinase 2 alpha 3 \\
\hline $\mathrm{NXPH} 4$ & $|6.6| 42424 \mid$ & Neurexophilin 4 \\
\hline UBQLN2 & 12.39677 & Ubiquilin 2 \\
\hline UTP3 & II.763036 & $\begin{array}{l}\text { UTP3, small-subunit processome } \\
\text { component }\end{array}$ \\
\hline MRPL57 & 10.75174746 & $\begin{array}{l}\text { Mitochondrial ribosomal protein } \\
\text { L57 }\end{array}$ \\
\hline GNGI 2 & 10.25738078 & G protein subunit gamma 12 \\
\hline ARF6 & $8.89|4356| 4$ & ADP ribosylation factor 6 \\
\hline EXOSC6 & 8.185877 & Exosome component 6 \\
\hline LINCO0II 6 & 8.037736957 & $\begin{array}{l}\text { Long intergenic non-protein coding } \\
\text { RNA II6 }\end{array}$ \\
\hline HASPIN & 7.989008 & $\begin{array}{l}\text { Histone } \mathrm{H} 3 \text { associated protein } \\
\text { kinase }\end{array}$ \\
\hline FASTKD5 & $7.872255 \mid 25$ & FAST kinase domains 5 \\
\hline CITED4 & 7.735957 & $\begin{array}{l}\mathrm{Cbp} / \mathrm{p} 300 \text { interacting transactivator } \\
\text { with Glu/Asp-rich carboxy-terminal } \\
\text { domain } 4\end{array}$ \\
\hline ZNF865 & 7.15529196 & Zinc finger protein 865 \\
\hline
\end{tabular}

Abbreviation: STC2, stanniocalcin 2 .
$R=0.193, P<0.001)$, UTP3 ( $R=0.208, P<0.001)$, mitochondrial ribosomal protein L57 (MRPL57; $R=0.213, P<0.001$ ), exosome component 6 (EXOSC6; $R=0.123, P=0.010$ ), histone $\mathrm{H} 3$ associated protein kinase (HASPIN; $R=0.279, P<0.001$ ),

Table 4 List of candidate genes downregulated by STC2 from RNA-seq

\begin{tabular}{|l|l|l|}
\hline Gene symbol & Fold change & Description \\
\hline RHOB & 0.008998524 & Ras homolog family member B \\
\hline PRNP & $0.01784524 I$ & Prion protein \\
\hline SFN & $0.0196685 I 4$ & Stratifin \\
\hline ZBED2 & 0.027575387 & Zinc finger BED-type containing 2 \\
\hline HIST3H2A & 0.031139269 & Histone cluster 3 H2A \\
\hline RNF26 & 0.034797645 & Ring finger protein 26 \\
\hline THAPII & 0.061529844 & THAP domain-containing II \\
\hline IRS2 & 0.066151925 & Insulin receptor substrate 2 \\
\hline DOLK & 0.077080648 & Dolichol kinase \\
\hline HIST2H2BE & 0.080842646 & Histone cluster 2 H2B family \\
& & member E \\
\hline ZNF770 & 0.081286499 & Zinc finger protein 770 \\
\hline ZNF358 & $0.10269538 I$ & Zinc finger protein 358 \\
\hline SFRP5 & 0.105743046 & Secreted frizzled-related protein 5 \\
\hline FJXI & 0.10776027 & Four jointed box I \\
\hline CDCA4 & 0.107929947 & Cell division cycle-associated 4 \\
\hline MYADM & 0.112652525 & $\begin{array}{l}\text { Myeloid-associated differentiation } \\
\text { marker }\end{array}$ \\
\hline ZNF830 & $0.12366216 I$ & Zinc finger protein 830 \\
\hline ATXN7L3B & $0.13435948 I$ & Ataxin 7 like 3B \\
\hline ZNF703 & 0.14828909 & Zinc finger protein 703 \\
\hline NRBF2 & 0.152734446 & Nuclear receptor-binding factor 2 \\
\hline HRCTI & 0.172996284 & Histidine rich carboxyl terminus I \\
\hline CCDC7I & 0.179029879 & Coiled-coil domain containing 7I \\
\hline APOL6 & 0.183460969 & Apolipoprotein L6 \\
\hline EFHD2 & $0.185244 I 42$ & EF-hand domain family member D2 \\
\hline Abbreviat & $5 T C 2$ & \\
\hline
\end{tabular}

Abbreviation: STC2, stanniocalcin 2. 
and $\mathrm{Cbp} / \mathrm{p} 300$ interacting transactivator with $\mathrm{Glu} / \mathrm{Asp}$-rich carboxy-terminal domain 4 (CITED4; $R=0.119, P=0.013$ ). Consistently, we also found significant negative correlation between STC2 and stratifin (SFN; $R=-0.281, P<0.001)$, nuclear receptor-binding factor 2 (NRBF2; $R=-0.261$, $P<0.001)$, HRCT1 $(R=-0.294, P<0.001)$, CCDC71 $(R=-0.124, P=0.010)$, apolipoprotein L6 (APOL6; $R=-0.190$, $P<0.001$ ), and EF-hand domain family member D2 (EFHD2; $R=-0.274, P<0.001$ ) expression (Figure 4C). We selected these genes for further observation.

Then we checked the mRNA levels of these genes in TCGA dataset. Consistent with our results from RNAseq, the expression of CCDC $85 \mathrm{~B}(8.452 \pm 0.695$ vs $7.660 \pm 0.586$, $P<0.001)$, TACSTD2 $(8.692 \pm 2.714$ vs $4.754 \pm 0.635$, $P<0.001)$, RNF113A (8.859 \pm 0.558 vs $8.165 \pm 0.333$, $P<0.001)$, NXPH4 (4.950 \pm 2.148 vs $1.861 \pm 0.899, P<0.001)$,

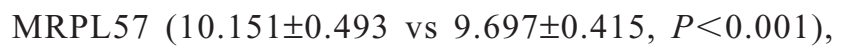
EXOSC6 (8.109 \pm 0.478 vs $7.846 \pm 0.314, P=0.012)$, and HASPIN (6.670 \pm 0.626 vs 5.633 $\pm 0.719, P<0.001)$ were dramatically upregulated in CRC samples when compared with adjacent normal tissues (Figure 5A). Although there were no statistically significant differences of UTP3 $(9.334 \pm 0.299$ vs 9.208 $\pm 0.263, P=0.078)$ and CITED4 $(6.493 \pm 1.305$ vs $6.110 \pm 1.017, P=0.195)$ expression between $C R C$ and normal control tissues, a similar trend was observed. In addition, as shown in Figure 5B, we validated decreased levels of SFN (11.415 \pm 0.836 vs $12.182 \pm 0.773, P<0.001)$, NRBF2 $(8.794 \pm 0.297$ vs $9.029 \pm 0.352, P=0.005)$, HRCT1 $(6.364 \pm 1.116$ vs $8.931 \pm 1.040, P<0.001)$, and APOL6 $(10.765 \pm 0.590$ vs $11.091 \pm 0.452, P=0.016)$ in CRC compared with normal tissues from TCGA dataset. However, no differences of CCDC71 (8.672 \pm 0.432 vs 8.869 \pm 0.390 , $P=0.060)$ and EFHD2 (12.021 \pm 0.460 vs $12.101 \pm 0.389$, $P=0.459)$ levels were observed between CRC and normal tissues. All these results suggested that STC2 might modulate the expression of a group of candidate genes.

\section{Discussion}

The TCGA cohort is a publicly available database, including 34 types of cancer tissue and normal tissue. ${ }^{3}$ In our study, we performed TCGA data analyses and found significant upregulation of STC2 in CRC. Furthermore, these results were validated in eight NCBI GEO datasets. The concordant performance in all datasets was as expected. In addition, it was indicated that the STC2 expression was significantly associated with tumor location, T stage, lymph node metastasis, and AJCC stage. In this study, our results demonstrated that patients with left-sided CRC had tumors with the elevated expression of STC2. Recently, many studies indicated that left-sided and right-sided CRC might belong to two distinctly different categories of cancer. ${ }^{21,22}$ They had different embryological background, molecular patterns, clinical features, outcomes, and treatment. ${ }^{21,22}$ For instance, it was reported that microsatellite-stable (MSS) CRC had a distinct phenotype such as left-sided location. ${ }^{23,24}$ All of our results suggested that $\mathrm{STC} 2$ might contribute to the tumorigenesis or progression of CRC.

In our previous study, we have demonstrated that STC2 overexpression was a biomarker for aggressiveness in highgrade serous ovarian cancer. ${ }^{14}$ Interestingly, it was consistent with our results in $\mathrm{CRC}$ in this study. Here, we found that high STC2 expression was associated with advanced T-stage, positive lymphatic involvement, and advanced AJCC stage. In the study of STC2 in esophageal squamous cell cancer (ESC), Kita et $\mathrm{al}^{25}$ found that STC2 mRNA expression was significantly associated with lymph node metastasis and lymphatic invasion in ESC. Consistently, we reported that high STC2 levels were correlated with positive lymph node metastasis in CRC in this study. Lymph node metastasis is a critical event in the progress of malignancies. ${ }^{26}$ It is a multistep process that includes detachment of cancer cells from their primary site, migration into lymphatic vessels, spread and settlement of tumor cells in the lymphatic system, escape from the lymphatic system, and finally colonization at a distant site. Several pathways and growth factors are involved in this process, ${ }^{26,27}$ including VEGF-C/VEGF-D/VEGFR-3 pathway, ${ }^{28}$ fibroblast growth factor 2 (FGF2), ${ }^{29}$ insulin-like growth factor (IGF), ${ }^{30}$ and so on. As we know, EMT also plays a very important in it. ${ }^{31}$ Here, we identified the relationship between STC2 expression and lymph node metastasis. We speculated that STC2 promoted lymphatic metastasis through VEGF-C/VEGF-D/ VEGFR-3 pathway and EMT-related molecules. However, its precise mechanism remains elusive. The molecular mechanism should be further investigated in future.

To further investigate the biological functions of STC2 in CRC, we compared the migration and invasion abilities of SW480 and DLD1 cell lines with or without STC2 overexpression. Promoting effects of STC2 on migration and invasion of CRC cells were observed. Consistently, the silence of STC2 reduced the migration and invasiveness of HCT116 and RKO cells in vitro. Here, this study identified a significant role of STC2 in CRC. STC2 facilitated the migration and invasion of CRC cells, and it was entirely 

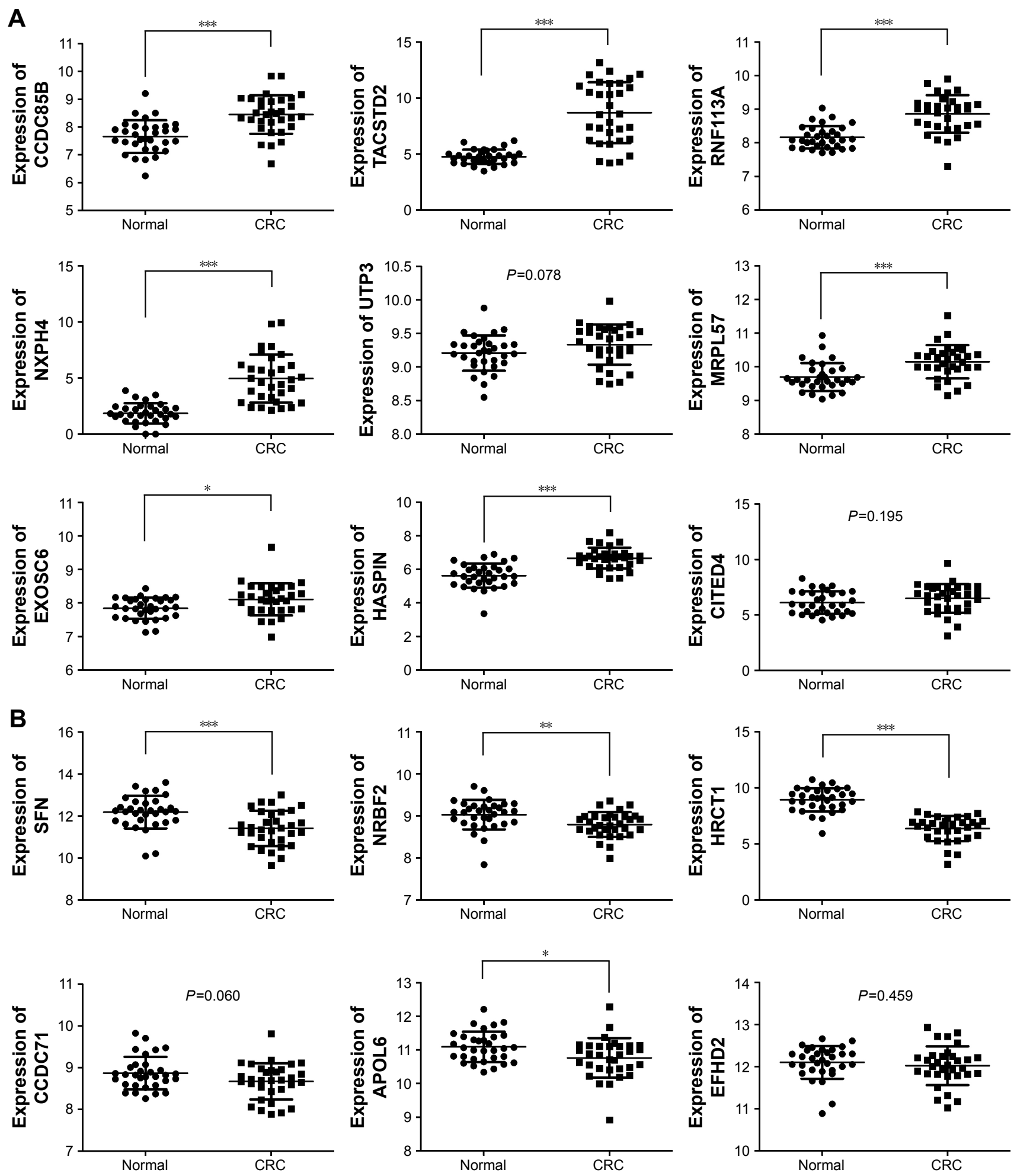

Figure 5 Altered expression of DEGs in CRC from TCGA.

Notes: (A) Dot plots showed the expression of CCDC85B, TACSTD2, RNFI I3A, NXPH4, UTP3, MRPL57, EXOSC6, HASPIN, and CITED4 in CRC and the adjacent normal tissues from TCGA dataset. (B) Dot plots showed the expression of SFN, NRBF2, HRCTI, CCDC7I, APOL6, and EFHD2 in CRC and the adjacent normal tissues from TCGA dataset. $* P<0.05 ; * * P<0.01 ; * * * P<0.001$.

Abbreviations: APOL6, apolipoprotein L6; CCDC7I, coiled-coil domain containing 7I; CCDC85B, coiled-coil domain containing 85B; CITED4, Cbp/p300 interacting transactivator with Glu/Asp-rich carboxy-terminal domain 4; CRC, colorectal cancer; DEG, differentially expressed gene; EFHD2, EF-hand domain family member D2; EXOSC6, exosome component 6; HASPIN, histone $\mathrm{H} 3$ associated protein kinase; HRCTI, histidine-rich carboxyl terminus I; MRPL57, mitochondrial ribosomal protein L57; NRBF2, nuclear receptor-binding factor 2; NXPH4, neurexophilin 4; RNFI I3A, ring finger protein II3A; SFN, stratifin; TACSTD2, tumor-associated calcium signal transducer 2; TCGA, The Cancer Genome Atlas. 
in agreement with the fact that high STC2 expression was associated with advanced $\mathrm{T}$ - and $\mathrm{N}$-stage.

Previous studies have suggested that STC2 expression plays an important role in the EMT of ovarian cancer ${ }^{32}$ and breast cancer. ${ }^{33}$ Here, we compared the relationships between the expression of STC2 and EMT-related genes using the TCGA datasets of CRC. The increased expression of mesenchymal markers and decreased expression of epithelial markers were identified in the STC2-high group. It highlighted a key role of STC2 in the regulation of EMT in CRC. The significantly elevated levels of MMP2, MMP3, and MMP9 were also observed in the STC2-high group here. Our findings showed an association between STC2 and EMT in CRC, and it raised the possibility that STC2 might partly drive EMT in CRC.

As STC2 overexpression played an important role in the CRC cells, there might be a number of differences in the gene expression profiles between STC2-high and STC2-low group. Thus, RNA-Seq was carried out on SW480 colon cancer cells with or without STC2 overexpression. The candidate genes identified by RNA-seq were further analyzed in the TCGA datasets. The results indicated that the expression levels of 15 genes tested were well matched between RNAseq and TCGA datasets. CCDC85B (also known as DIPA), which could be found on the centrosome, directly interacted with p78 and influenced malignant transformation by modulating gene transcription. ${ }^{34}$ TACSTD2 is a single transmembrane surface glycoprotein, which is highly expressed in various carcinoma tissues. Elevated TACSTD2 (also known as TROP-2) level was associated with poor survival in various tumors of epithelial origin, including CRC. ${ }^{35}$ Most interestingly, the results from preclinical studies demonstrated that antibody-drug conjugates (ADCs) against Trop-2 were effective for treatment in several epithelial cancers. ${ }^{36}$ As an oncoprotein, RNF113A promoted cell proliferation, migration, and invasiveness in esophageal squamous cell carcinoma (ESCC).$^{37}$ In the study of genome-wide gene expression profiling of CRC and adjacent tissues by Sun and Qian, ${ }^{38}$ UTP3 was identified as 1 of 20 hub genes in CRC. It suggested that UTP3 plays a vital role in the development of CRC. Hawkins et al reported that EXOSC6 was identified as one of the five novel peptides presented by sHLA-A*0201 in breast cancer cells. It could be recognized by circulating $\mathrm{CD}^{+} \mathrm{T}$ lymphocytes and appeared to be a potential target in the field of cancer immune therapy. ${ }^{39}$ As we know, HASPIN is a serine/threonine kinase that directly phosphorylates histone $\mathrm{H} 3$ at threonine 3 during mitosis. ${ }^{40}$ Therefore, HASPIN has been the focus of potential drugs for treating cancer recently, and its inhibitors possess antitumor effects. ${ }^{40}$ CITED4 interacts with CBP/P300 and disrupts the binding between hypoxia inducible factor 1 subunit alpha (HIF $1 \alpha$ ) and CBP/P300, ${ }^{41}$ and it leads to the inhibition of HIF $1 \alpha$-mediated transcription that is involved in hypoxia signaling. ${ }^{42}$ In CRC, Rogers et $\mathrm{al}^{43}$ found that knockdown of CITED4 inhibited cell proliferation and deregulated the expression of a group of genes involved in adherens and tight junctions. SFN, a member of the 14-3-3 family, was found to be downregulated in a large number of epithelial cancers. ${ }^{44}$ It is involved in multiple biological processes, including cell cycle, apoptosis, differentiation, and cell survival. ${ }^{45}$ NRBF2 was identified as a component of the class III phosphatidylinositol 3-kinase complex I (PI3KC3-C1), suggesting that NRBF2 was important in autophagy. ${ }^{46}$ Liu et $\mathrm{al}^{47}$ previously reported that APOL6 induced mitochondria-mediated apoptosis in DLD-1 CRC cell line. EFHD2, also known as swiprosin-1 (SWS1), was also found to be involved in tumorigenesis. It acted dual role as a negative or positive regulator in NF-kB pathway. In addition, it induced apoptosis in WEHI231 cell. However, it promoted metastasis in B16F10 cells. ${ }^{48}$ Taken together, these data suggested that STC2 promoted CRC progress by regulating a group of target genes.

\section{Conclusion}

Overall, our data revealed that STC2 showed significantly increased expression in CRC patients from public database and promoted cell migration and invasion in vitro. High STC2 levels closely associated with tumor location, T-stage, lymphatic metastasis, and AJCC stage. Correlation between STC2 and EMT-related markers was also observed here. Our data strongly indicated that STC2 might represent a novel and potential therapeutic target for CRC.

\section{Acknowledgment}

This study was supported by project grants from the National Natural Science Foundation of China (81772527, 81672342, 81472819, 81302073, and 81302072) and the Zhejiang Provincial Natural Science Foundation of China (LY17H160034).

\section{Disclosure}

The authors report no conflicts of interest in this work.

\section{References}

1. Siegel RL, Miller KD, Jemal A. Cancer statistics, 2018. CA Cancer J Clin. 2018;68(1):7-30.

2. Dienstmann R, Vermeulen L, Guinney J, Kopetz S, Tejpar S, Tabernero J. Consensus molecular subtypes and the evolution of precision medicine in colorectal cancer. Nat Rev Cancer. 2017;17(2):79-92.

3. Cancer Genome Atlas Research Network, Weinstein JN, Collisson EA, et al. The Cancer Genome Atlas Pan-Cancer analysis project. Nat Genet. 2013;45(10):1113-1120. 
4. Barrett T, Wilhite SE, Ledoux P, et al. NCBI GEO: archive for functional genomics data sets - update. Nucleic Acids Res. 2013;41(Database issue):D991-D995.

5. Matsuyama T, Ishikawa T, Mogushi K, et al. MUC12 mRNA expression is an independent marker of prognosis in stage II and stage III colorectal cancer. Int J Cancer. 2010;127(10):2292-2299.

6. Gaedcke J, Grade M, Jung K, et al. Mutated KRAS results in overexpression of DUSP4, a MAP-kinase phosphatase, and SMYD3, a histone methyltransferase, in rectal carcinomas. Genes Chromosomes Cancer. 2010;49(11):1024-1034.

7. Tsukamoto $\mathrm{S}$, Ishikawa $\mathrm{T}$, Iida $\mathrm{S}$, et al. Clinical significance of osteoprotegerin expression in human colorectal cancer. Clin Cancer Res. 2011;17(8):2444-2450.

8. Alhopuro P, Sammalkorpi H, Niittymäki I, et al. Candidate driver genes in microsatellite-unstable colorectal cancer. Int J Cancer. 2012; 130(7):1558-1566.

9. Sun Y, Shen S, Tang H, et al. miR-429 identified by dynamic transcriptome analysis is a new candidate biomarker for colorectal cancer prognosis. OMICS. 2014;18(1):54-64.

10. Ryan BM, Zanetti KA, Robles AI, et al. Germline variation in NCF4, an innate immunity gene, is associated with an increased risk of colorectal cancer. Int J Cancer. 2014;134(6):1399-1407.

11. Uribe-Lewis S, Stark R, Carroll T, et al. 5-hydroxymethylcytosine marks promoters in colon that resist DNA hypermethylation in cancer Genome Biol. 2015;16:69.

12. Ding L, Wang L, Sui L, et al. Claudin-7 indirectly regulates the integrin/ FAK signaling pathway in human colon cancer tissue. J Hum Genet. 2016;61(8):711-720.

13. Chang AC, Jellinek DA, Reddel RR. Mammalian stanniocalcins and cancer. Endocr Relat Cancer. 2003;10(3):359-373.

14. Wu J, Lai M, Shao C, Wang J, Wei JJ. STC2 overexpression mediated by HMGA2 is a biomarker for aggressiveness of high-grade serous ovarian cancer. Oncol Rep. 2015;34(3):1494-1502.

15. Arigami T, Uenosono Y, Ishigami S, et al. Clinical significance of stanniocalcin 2 expression as a predictor of tumor progression in gastric cancer. Oncol Rep. 2013;30(6):2838-2844.

16. Miyazaki S, Kikuchi H, Iino I, et al. Anti-VEGF antibody therapy induces tumor hypoxia and stanniocalcin 2 expression and potentiates growth of human colon cancer xenografts. Int J Cancer. 2014;135(2): 295-307.

17. Chen B, Zeng X, He Y, et al. STC2 promotes the epithelial-mesenchymal transition of colorectal cancer cells through AKT-ERK signaling pathways. Oncotarget. 2016;7(44):71400-71416.

18. Ieta K, Tanaka F, Yokobori T, et al. Clinicopathological significance of stanniocalcin 2 gene expression in colorectal cancer. Int J Cancer. 2009;125(4):926-931.

19. Yuan Q, Zhan L, Zhang LL, et al. Stanniocalcin 2 induces oxaliplatin resistance in colorectal cancer cells by upregulating P-glycoprotein. Can J Physiol Pharmacol. 2016;94(9):929-935.

20. Zhang ZH, Wu YG, Qin CK, et al. Stanniocalcin 2 expression predicts poor prognosis of hepatocellular carcinoma. Oncol Lett. 2014;8(5): 2160-2164.

21. Mik M, Berut M, Dziki L, Trzcinski R, Dziki A. Right- and left-sided colon cancer - clinical and pathological differences of the disease entity in one organ. Arch Med Sci. 2017;13(1):157-162.

22. Guinney J, Dienstmann R, Wang X, et al. The consensus molecular subtypes of colorectal cancer. Nat Med. 2015;21(11):1350-1356.

23. Missiaglia E, Jacobs B, D’Ario G, et al. Distal and proximal colon cancers differ in terms of molecular, pathological, and clinical features. Ann Oncol. 2014;25(10):1995-2001.

24. Li P, Xiao Z, Braciak TA, Ou Q, Chen G, Oduncu FS. A relationship to survival is seen by combining the factors of mismatch repair status, tumor location and age of onset in colorectal cancer patients. PLoS One. 2017;12(3):e0172799.

25. Kita Y, Mimori K, Iwatsuki M, et al. STC2: a predictive marker for lymph node metastasis in esophageal squamous-cell carcinoma. Ann Surg Oncol. 2011;18(1):261-272.
26. Karaman S, Detmar M. Mechanisms of lymphatic metastasis. J Clin Invest. 2014;124(3):922-928.

27. Achen MG, Stacker SA. Molecular control of lymphatic metastasis. Ann N Y Acad Sci. 2008;1131:225-234.

28. He Y, Rajantie I, Pajusola K, et al. Vascular endothelial cell growth factor receptor 3-mediated activation of lymphatic endothelium is crucial for tumor cell entry and spread via lymphatic vessels. Cancer Res. 2005;65(11):4739-4746.

29. Cao R, Ji H, Feng N, et al. Collaborative interplay between FGF-2 and VEGF-C promotes lymphangiogenesis and metastasis. Proc Natl Acad Sci U S A. 2012;109(39):15894-15899.

30. Björndahl M, Cao R, Nissen LJ, et al. Insulin-like growth factors 1 and 2 induce lymphangiogenesis in vivo. Proc Natl Acad Sci US A. 2005;102(43):15593-15598

31. Karlsson MC, Gonzalez SF, Welin J, Fuxe J. Epithelial-mesenchymal transition in cancer metastasis through the lymphatic system. Mol Oncol. 2017;11(7):781-791.

32. Law AY, Wong CK. Stanniocalcin-2 promotes epithelial-mesenchymal transition and invasiveness in hypoxic human ovarian cancer cells. Exp Cell Res. 2010;316(20):3425-3434.

33. Hou J, Wang Z, Xu H, et al. Stanniocalicin 2 suppresses breast cancer cell migration and invasion via the $\mathrm{PKC} /$ claudin-1-mediated signaling. PLoS One. 2015;10(4):e0122179.

34. Du X, Wang Q, Hirohashi Y, Greene MI. DIPA, which can localize to the centrosome, associates with p78/MCRS1/MSP58 and acts as a repressor of gene transcription. Exp Mol Pathol. 2006;81(3): 184-190.

35. Ohmachi T, Tanaka F, Mimori K, Inoue H, Yanaga K, Mori M. Clinical significance of TROP2 expression in colorectal cancer. Clin Cancer Res. 2006;12(10):3057-3063.

36. Cardillo TM, Govindan SV, Sharkey RM, Trisal P, Goldenberg DM. Humanized anti-Trop-2 IgG-SN-38 conjugate for effective treatment of diverse epithelial cancers: preclinical studies in human cancer xenograft models and monkeys. Clin Cancer Res. 2011;17(10): 3157-3169.

37. Wang L, Hou Z, Hasim A, et al. RNF113A promotes the proliferation, migration and invasion, and is associated with a poor prognosis of esophageal squamous cell carcinoma. Int J Oncol. 2018;52(3): 861-871.

38. Sun LC, Qian HX. Screening for implicated genes in colorectal cancer using whole-genome gene expression profiling. Mol Med Rep. 2018;17(6):8260-8268.

39. Hawkins OE, Vangundy RS, Eckerd AM, et al. Identification of breast cancer peptide epitopes presented by HLA-A*0201. J Proteome Res. 2008;7(4):1445-1457.

40. Amoussou NG, Bigot A, Roussakis C, Robert JH. Haspin: a promising target for the design of inhibitors as potent anticancer drugs. Drug Discov Today. 2018;23(2):409-415.

41. Bragança J, Swingler T, Marques FI, et al. Human CREB-binding protein/p300-interacting transactivator with ED-rich tail (CITED) 4, a new member of the CITED family, functions as a co-activator for transcription factor AP-2. J Biol Chem. 2002;277(10):8559-8565.

42. Fox SB, Bragança J, Turley H, et al. CITED4 inhibits hypoxia-activated transcription in cancer cells, and its cytoplasmic location in breast cancer is associated with elevated expression of tumor cell hypoxia-inducible factor 1alpha. Cancer Res. 2004;64(17):6075-6081.

43. Rogers MA, Kalter V, Marcias G, Zapatka M, Barbus S, Lichter P. CITED4 gene silencing in colorectal cancer cells modulates adherens/ tight junction gene expression and reduces cell proliferation. J Cancer Res Clin Oncol. 2016;142(1):225-237.

44. Cunningham SC, Kamangar F, Kim MP, et al. Claudin-4, mitogenactivated protein kinase kinase 4 , and stratifin are markers of gastric adenocarcinoma precursor lesions. Cancer Epidemiol Biomarkers Prev. 2006;15(2):281-287.

45. Kim Y, Shiba-Ishii A, Nakagawa T, et al. Stratifin regulates stabilization of receptor tyrosine kinases via interaction with ubiquitin-specific protease 8 in lung adenocarcinoma. Oncogene. Epub 2018 Jun 7. 
46. Young LN, Cho K, Lawrence R, Zoncu R, Hurley JH. Dynamics and architecture of the NRBF2-containing phosphatidylinositol 3-kinase complex I of autophagy. Proc Natl Acad Sci U S A. 2016; 113(29):8224-8229.

47. Liu Z, Lu H, Jiang Z, Pastuszyn A, Hu CA. Apolipoprotein 16, a novel proapoptotic Bcl-2 homology 3-only protein, induces mitochondria-mediated apoptosis in cancer cells. Mol Cancer Res. 2005; 3(1):21-31.
48. Thylur RP, Gowda R, Mishra S, Jun CD. Swiprosin-1: Its Expression and Diverse Biological Functions. J Cell Biochem. 2018;119(1):150-156.

\section{Publish your work in this journal}

OncoTargets and Therapy is an international, peer-reviewed, open access journal focusing on the pathological basis of all cancers, potential targets for therapy and treatment protocols employed to improve the management of cancer patients. The journal also focuses on the impact of management programs and new therapeutic agents and protocols on

patient perspectives such as quality of life, adherence and satisfaction. The manuscript management system is completely online and includes a very quick and fair peer-review system, which is all easy to use. Visit http://www.dovepress.com/testimonials.php to read real quotes from published authors. 